\title{
The underlying mechanisms for development of hypertension in the metabolic syndrome
}

\author{
Hidekatsu Yanai ${ }^{* 1}$, Yoshiharu Tomono ${ }^{1}$, Kumie Ito ${ }^{1}$, Nobuyuki Furutani ${ }^{1}$, \\ Hiroshi Yoshida ${ }^{2}$ and Norio Tada ${ }^{1}$
}

Address: ${ }^{1}$ Department of Internal Medicine, The Jikei University School of Medicine, Chiba, Japan and ${ }^{2}$ Department of Laboratory Medicine, The Jikei University School of Medicine, Chiba, Japan

Email: Hidekatsu Yanai* - yanaih@jikei.ac.jp; Yoshiharu Tomono - tomono@jikei.ac.jp; Kumie Ito - ito@jikei.ac.jp; Nobuyuki Furutani - furutanin@jikei.ac.jp; Hiroshi Yoshida - hyoshida@jikei.ac.jp; Norio Tada - n-tada27@jikei.ac.jp

* Corresponding author

Published: 17 April 2008

Nutrition Journal 2008, 7:10 doi:10.1/86/1475-289/-7-10
Received: 16 December 2007

Accepted: 17 April 2008

This article is available from: http://www.nutritionj.com/content/7///10

(C) 2008 Yanai et al; licensee BioMed Central Ltd.

This is an Open Access article distributed under the terms of the Creative Commons Attribution License (http://creativecommons.org/licenses/by/2.0), which permits unrestricted use, distribution, and reproduction in any medium, provided the original work is properly cited.

\begin{abstract}
High blood pressure is an important constituent of the metabolic syndrome. However, the underlying mechanisms for development of hypertension in the metabolic syndrome are very complicated and remain still obscure. Visceral/central obesity, insulin resistance, sympathetic overactivity, oxidative stress, endothelial dysfunction, activated renin-angiotensin system, increased inflammatory mediators, and obstructive sleep apnea have been suggested to be possible factors to develop hypertension in the metabolic syndrome. Here, we will discuss how these factors influence on development of hypertension in the metabolic syndrome.
\end{abstract}

\section{Introduction}

The metabolic syndrome is characterized by the simultaneous occurrence of metabolic abnormalities including obesity, glucose intolerance, dyslipidemia, and hypertension, that result in a marked increase in cardiovascular morbidity and mortality [1-3]. High blood pressure is a classical feature of the metabolic syndrome, and it has been reported that the metabolic syndrome is present in up to one third of hypertensive patients [4,5]. Therefore, high blood pressure is included in the definition for the metabolic syndrome that presented by the World Health Organization, the National Cholesterol Education Program, the International Diabetes Federation, and the American Heart Association/National Heart, Lung, and Blood Institutes [1-3,6]. Blood pressure levels are strongly associated with visceral obesity and insulin resistance [7], which are the main pathophysiologic features underlying the metabolic syndrome. Here, we will discuss the under- lying mechanisms for development of hypertension in the metabolic syndrome.

The underlying mechanisms for development of hypertension in the metabolic syndrome

Proposed mechanisms for development of hypertension in the metabolic syndrome were shown in Figure 1.

\section{Visceral obesity}

Excess food intake and physical inactivity underlie the growing worldwide epidemic of obesity. Hyperglycemia, hyperlipidemia, and hypertension are common in obese individuals $[8,9]$. Visceral obesity has been suggested to play a fundamental role in the simultaneous development of these disorders [10]. Recent studies have demonstrated that adipose tissue is a major endocrine organ that secrets a variety of bioactive substances, termed adipocytokines. Adipocytokines secretion are altered as obesity develops, 


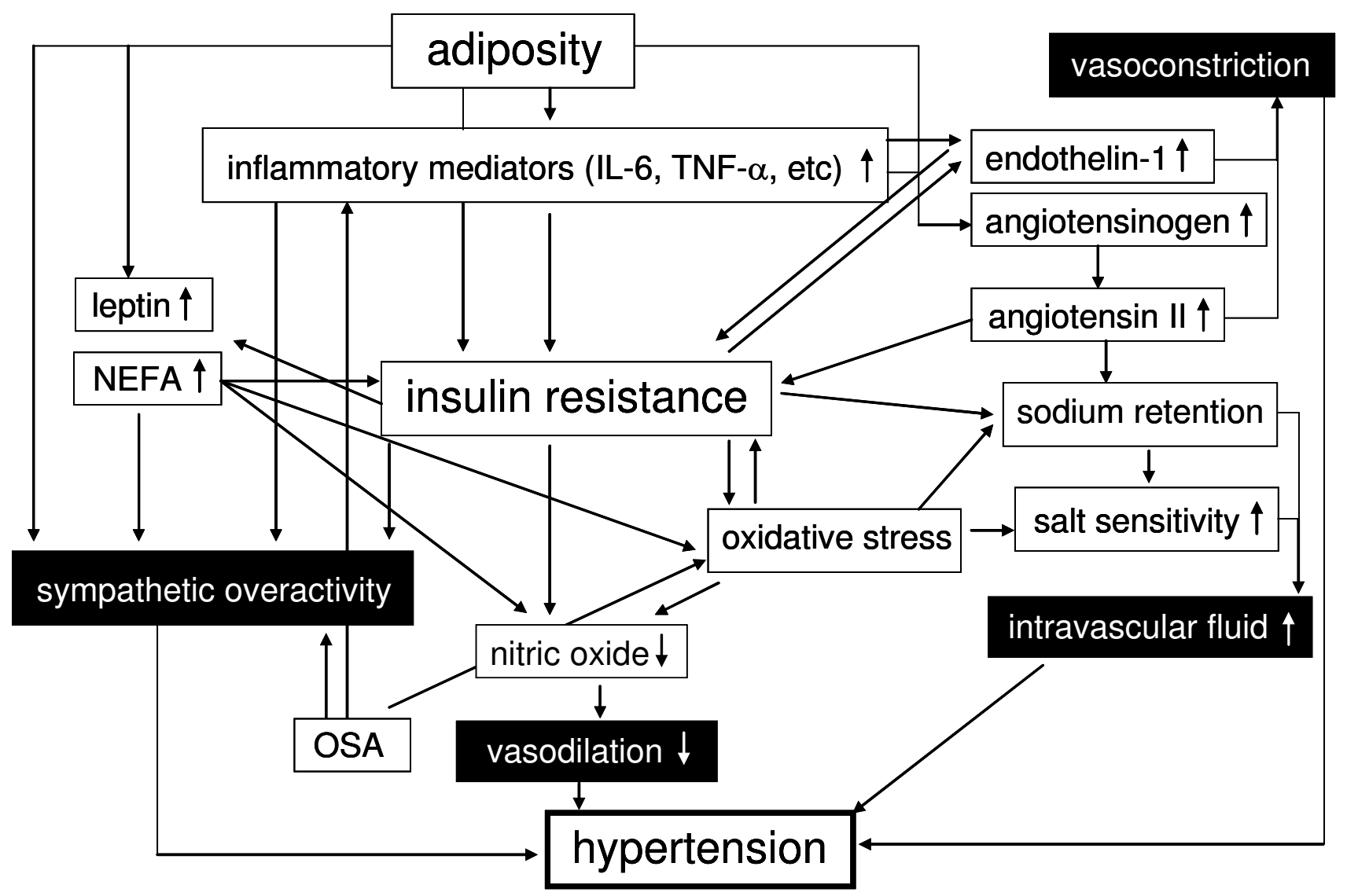

Figure I

Proposed mechanisms for development of hypertension in the metabolic syndrome. IL-6, interleukin-6; NEFA, non-esterified fatty acids; TNF- $\alpha$, tumor necrosis factor- $\alpha$; OSA, obstructive sleep apnea.

which may induce the metabolic disorders. As shown in Figure 1, accumulated visceral adipose tissue produce and secrete a number of adipocytokines, such as leptin, tumor necrosis factor- $\alpha$ (TNF- $\alpha$ ), interleukin-6 (IL-6), angiotensinogen, and non-esterified fatty acids (NEFA), which induce development of hypertension [11]. Visceral obesity is the main cause of the metabolic syndrome, and is associated with development of hypertension in the metabolic syndrome via a variety of pathways (Figure 1).

\section{Insulin resistance}

Insulin resistance is the main pathophysiologic feature of the metabolic syndrome. Several mechanisms connect insulin resistance with hypertension in the metabolic syndrome. An anti-natriuretic effect of insulin has been established by accumulating data indicating that insulin stimulates renal sodium re-absorption [12-14]. This antinatriuretic effect is preserved, and may be increased in individuals with insulin resistance, and this effect may play an important role for development of hypertension in the metabolic syndrome [15]. Strazzullo P, et al. inves- tigated the relationship between the metabolic syndrome and renal tubular sodium handling [16]. In their study, proximal fractional sodium re-absorption (FPRNa) was significantly greater in individuals with the metabolic syndrome, as compared with those without the metabolic syndrome [16]. Further, in untreated obese individuals, age-adjusted FPRNa was significantly greater in individuals with insulin resistance as compared with those without insulin resistance [16]. Insulin resistance is also associated with development of salt-sensitive hypertension through the anti-natriuretic effect of insulin [17].

In vitro studies have shown that insulin stimulates both endothelin-1 production and its action on the vascular wall [18]. In vivo study has also demonstrated that high serum insulin level is associated with an increase in circulating endothelin-1 in healthy and insulin-resistant individuals [18]. Endothelin-1 receptor antagonism effectively reduced blood pressure in animal models of insulin resistance and hypertension [18], suggesting a sig- 
nificance of endothelin-1 in the pathogenesis of hypertension in insulin resistance.

\section{Sympathetic overactivity}

Serum catecholamine concentrations and muscle sympathetic nervous activity (MSNA) were significantly increased in obese individuals as compared with lean individuals [19], and MSNA in subjects with central obesity were significantly greater than those in individuals with peripheral obesity [19]. Elevated resting heat rates $[20,21]$, and baroreflex dysfunction have been reported to play an important role in development of hypertension in the metabolic syndrome [22]. Individuals with obstructive sleep apnea (OSA) have a high prevalence of the metabolic syndrome $[23,24]$, and OSA has been reported to be associated with sympathetic overactivity. Obese individuals exhibit an activated renin-angiotensin system [25], which induces hypertension. The renin-angiotensin system and sympathetic nervous system are linked by a positive feedback relationship [26]. Insulin resistance, increased leptin and NEFA levels have been indicated to be possible factors augmenting sympathetic nervous activation in the metabolic syndrome [27]. NEFA has been reported to raise blood pressure, heart rate, and $\alpha 1$-adrenoceptor vasoreactivity, while reducing baroreflex sensitivity, endothelium-dependent vasodilatation, and vascular compliance [28]. Insulin resistance increases plasma leptin levels, and leptin has been reported to elevate sympathetic nervous activity, suggesting that leptin-dependent sympathetic nervous activation may contribute to an obesity-associated hypertension [29]. Accumulating data suggest that metabolic syndrome is associated with markers of adrenergic overdrive [30].

\section{Oxidative stress and endothelial dysfunction}

In rats with the metabolic syndrome, induced by chronic consumption of a high fat, high refined sugar [31], hypertension is associated with oxidative stress [32], avid nitric oxide (NO) inactivation, and down-regulation of NO synthase (NOS) isoforms and endothelial NOS activator [32], suggesting that oxidative stress and endothelial dysfunction may be strongly associated with development of hypertension in the metabolic syndrome. Further, recent evidences suggest that oxidative stress, which is elevated in the metabolic syndrome [33], is associated with sodium retention and salt sensitivity [34].

In non-diabetic human subjects, lipid peroxidation, represented by plasma thiobarbituric acid reactive substance and urinary 8 -epi-prostaglandin-F2 $\alpha$, were significantly and positively correlated with body mass index and waist circumference, indicating that fat accumulation is correlated with oxidative stress in humans [33]. Cross-sectional data from 2,002 non-diabetic subjects of the communitybased Framingham Offspring Study has shown that sys- temic oxidative stress is associated with insulin resistance [35]. Insulin resistance induces an impairment in phosphatidylinositol 3-kinase (PI3K) - dependent signaling, which in endothelium may cause imbalance between production of nitric oxide and secretion of endothelin-1, leading to endothelial dysfunction [36]. Epidemiological studies strongly support a reciprocal relationship between endothelial dysfunction, which contributes to development of hypertension, and insulin resistance [36]. In a prospective cohort study, each one-unit decrease of flowmediated dilatation was associated with a significant $16 \%$ (95\% confidence interval: $12-33 \%$ ) increase in the multiple-adjusted relative risk of incident hypertension, suggesting that an impaired endothelial vasomotor function precedes and predicts the future development of hypertension [37].

\section{Activated renin-angiotensin system}

The renin-angiotensin system (RAS) plays a crucial role in blood pressure regulation, by affecting renal function and by modulating vascular tone. The activity of the RAS appears to be regulated by food intake, and overfeeding of rodents has been reported to lead to increased formation of angiotensin II in adipocytes [38]. Angiotensinogen, angiotensin converting enzyme, and type 1 angiotensin receptor gene are widely expressed in human adipose tissue [39], and production of angiotensin II and angiotensinogen in adipose tissue may be increased in obese subjects. Goodfriend TL, et al. measured plasma aldosterone levels in adults with various values of body mass index [40]. Plasma aldosterone level was higher in obese subjects, but could not be explained by renin and potassium [40]. The best predictor for plasma aldosterone level was abdominal obesity [40]. Elevated renin and aldosterone levels have been observed in subjects with multiple risk factors as compared with those without multiple risk factors [41]. Plasma aldosterone has been reported to be significantly associated with the metabolic syndrome and also with obesity-related hypertension $[42,43]$.

There are accumulating data indicating that angiotensin II inhibits the action of insulin via angiotensin type 1 receptor, in vascular muscle tissue, by interfering with insulin signaling through PI3K and its downstream protein kinase B (Akt) signaling pathway [44]. This inhibitory action of angiotensin II is mediated through stimulation of RhoA activity and oxidative stress [44]. Increased RhoA activity and reactive oxygen species inhibit PI3K/Akt signaling, resulting in decreased NO production in endothelial cell and increased vasoconstriction [44]. Activated RAS may contribute to development of hypertension in the metabolic syndrome. 


\section{Increased inflammatory mediators}

Recent cohort studies have demonstrated that high-sensitivity C-reactive protein (hsCRP) independently presents additive prognostic values at all levels of metabolic syndrome [45]. Ridker PM, et al. suggest a consideration of adding hsCRP as a clinical criterion for metabolic syndrome [45]. Abnormalities in inflammatory mediators have been also reported to be implicated with development of hypertension. A positive relationship between increased serum levels of CRP and the risk for development of incident hypertension in participants of the Women's Health Study [46]. Grundy SM suggests a significant association among inflammation, hypertension, and the metabolic syndrome [47].

TNF- $\alpha$ is involved in the pathophysiology of hypertension in the metabolic syndrome. TNF- $\alpha$ stimulates the production of endothelin-1 and angiotensinogen [48,49]. The TNF- $\alpha$ gene locus seems to be involved in human insulin resistance-mediated hypertension [50]. Serum TNF- $\alpha$ concentration has been reported to be positively correlated with systolic blood pressure and insulin resistance in humans [51], and increased TNF- $\alpha$ secretion has been observed in monocytes from hypertensive patients [52].

IL-6 is a multifunctional cytokine which mediates inflammatory responses. Recent study demonstrated that blood pressure was a significant and independent predictor of serum IL-6 concentrations in women [53]. IL-6 stimulates the central nervous system and sympathetic nervous system, which may result in hypertension [54,55]. The administration of IL- 6 leads to elevation in heart rate and serum norepinephrine levels in women [56]. Further, IL-6 induces an increase in plasma angiotensinogen and angiotensin II [57], leading to development of hypertension.

\section{Obstructive sleep apnea}

Of 146 patients with OSA, 88 (60\%) had the metabolic syndrome, whereas 33 of 82 patients $(40 \%)$ without OSA had the metabolic syndrome, suggesting high prevalence of the metabolic syndrome in OSA patients [58]. The proportion with hypertension was significantly higher in the OSA group (77\%) than in the non-OSA group (51\%), indicating a significant association between OSA and hypertension [58]. Kono $\mathrm{M}$ et al. also demonstrated that the percentage of hypertensive patients were significantly higher in the OSA group $(45 \%)$ than in the non-OSA group (15\%) [59]. There are accumulating evidences suggesting a significant association between the metabolic syndrome and OSA or its components [60]. Patients with OSA are often considered to be obese, however, Kono $\mathrm{M}$ et al. reported that OSA was associated with hypertension, dyslipidemia, and hyperglycemia, independent of visceral obesity [59]. Recent epidemiological and clinical data suggest a crucial role of OSA in development of hypertension, however, associations of OSA with insulin resistance and dyslipidemia are controversial [60]. Visceral obesity remains a confounding issue in studying the association between OSA and the metabolic syndrome.

OSA is characterized by an increased number of sympathetic bursts, a raised plasma norepinephrine concentration, and a reduction in baroreflex sensitivity $[23,24,61]$, which leaves no doubt as to the existence of sympathetic activation induced by baroreflex dysfunction, much like what has been observed in the metabolic syndrome. In OSA, the nocturnal episodes of hypoxia and hypercapnia induce the stimulation of arterial chemoreceptors, which could induce sympathostimulating effects [61]. Hyperleptinemia, insulin resistance, elevated angiotensin II and aldosterone levels, oxidative stress, inflammation, and endothelial dysfunction have been also suggested to be possible mechanisms whereby OSA may contribute to development of hypertension [62].

\section{Conclusion}

Visceral obesity, insulin resistance, oxidative stress, endothelial dysfunction, activated renin-angiotensin system, increased inflammatory mediators, and obstructive sleep apnea have been proposed to be possible factors to develop hypertension in the metabolic syndrome. These factors may induce sympathetic overactivity, vasoconstriction, increased intravascular fluid, and decreased vasodilatation, leading to development of hypertension in the metabolic syndrome.

\section{References}

I. Expert Panel on Detection, Evaluation, and Treatment of High Blood Cholesterol in Adults: Executive Summary of the Third Report of the National Cholesterol Education Program (NCEP) Expert Panel on Detection, Evaluation, and Treatment of High Blood Cholesterol in Adults (Adult Treatment Panel III). JAMA 200I, 285:2486-2497.

2. World Health Organization: Definition, Diagnosis and Classification of Diabetes Mellitus and Its Complication. Part I: Diagnosis and Classification of Diabetes Mellitus. World Health Organization, Geneva; 1999.

3. Guerrero-Romero F, Rodriguez-Moran M: Concordance between the 2005 International Diabetes Federation definition for diagnosing metabolic syndrome with the National Cholesterol Education Program Adult Treatment Panel III and the World Health Organization definitions. Diabetes Care 2005, 28:2588-2589.

4. Cuspidi C, Meani S, Fusi V, Severgnini B, Valerio C, Catini E, Leonetti G, Magrini F, Zanchetti A: Metabolic syndrome and target organ damage in untreated essential hypertensives. J Hypertens 2004 , 22:199|-1998.

5. Schillaci G, Pirro M, Vaudo G, Gemelli F, Marchesi S, Porcellati C, Mannarino E: Prognostic value of the metabolic syndrome in essential hypertension. J Am Coll Cardiol 2004, 43: 1817-I822.

6. Grundy SM, Brewer HB Jr, Cleeman JI, Smith SC Jr, Lenfant C, American Heart Association; National Heart, Lung, and Blood Institute: Definition of metabolic syndrome: Report of the National Heart, Lung, and Blood Institute/American Heart Association conference on scientific issues related to definition. Circulation 2004, 109:433-438.

7. Ferrannini E, Natali A, Capaldo B, Lehtovirta M, Jacob S, Yki-Järvinen $H$ : Insulin resistance, hyperinsulinemia, and blood pressure: 
role of age and obesity. European Group for the Study of Insulin Resistance (EGIR). Hypertension 1997, 30: I | 44- I | 49.

8. Kaplan NM: The deadly quartet. Upper-body obesity, glucose intolerance, hypertriglyceridemia, and hypertension. Arch Intern Med 1989, 149:1514-I520.

9. Reaven GM: Role of insulin resistance in human disease (syndrome X): an expanded definition. Annu Rev Med 1993. 44: $|2|-|3|$.

10. Fujioka S, Matsuzawa $\mathrm{Y}$, Tokunaga K, Tarui S: Contribution of intra-abdominal fat accumulation to the impairment of glucose and lipid metabolism in human obesity. Metabolism 1987, 36:54-59.

II. Katagiri H, Yamada T, Oka Y: Adiposity and cardiovascular disorders: disturbance of the regulatory system consisting of humoral and neuronal signals. Circ Res 2007, 101:27-39.

12. Miller JH, Bogdonoff MD: Antidiuresis associated with administration of insulin. J Appl Physiol 1954, 6:509-5 I2.

13. Nizet A, Lefebvre P, Crabbe J: Control by insulin of sodium potassium and water excretion by the isolated dog kidney. Pflugers Arch 1971, 323: I I-20.

14. Defronzo RA, Cooke CR, Andres R, Faloona GR, Davis PJ: The effect of insulin on renal handling of sodium, potassium, calcium, and phosphate in man. I Clin Invest 1975, 55:845-855.

15. Sechi LA: Mechanisms of insulin resistance in rat models of hypertension and their relationships with salt sensitivity. J Hypertens 1999, 17:1229-1237.

16. Strazzullo P, Barbato A, Galletti F, Barba G, Siani A, lacone R, D'Elia L, Russo O, Versiero M, Farinaro E, Cappuccio FP: Abnormalities of renal sodium handling in the metabolic syndrome. Results of the Olivetti Heart Study. J Hypertens 2006, 24:1633-1639.

17. Rocchini AP: Obesity hypertension, salt sensitivity and insulin resistance. Nutr Metab Cardiovasc Dis 2000, 10:287-294.

18. Sarafidis PA, Bakris GL: Insulin and endothelin: an interplay contributing to hypertension development? J Clin Endocrinol Metab 2007, 92:379-385

19. Grassi G, Dell'Oro R, Facchini A, Quarti Trevano F, Bolla GB, Mancia $G$ : Effect of central and peripheral body fat distribution on sympathetic and baroreflex function in obese normotensives. J Hypertens 2004, 22:2363-2369.

20. Julius S, Krause L, Schork NJ, Mejia AD, Jones KA, van de Ven C, Johnson EH, Sekkarie MA, Kjeldsen SE, Petrin J: Hyperkinetic borderline hypertension in Tecumseh, Michigan. J Hypertens 1991, 9:77-84.

21. Julius S, Jamerson K: Sympathetics, insulin resistance and coronary risk in hypertension: the 'chicken-and-egg' question. I Hypertens 1994, 1 2:495-502.

22. Grassi G, Dell'Oro R, Quarti-Trevano F, Scopelliti F, Seravalle G, Paleari F, Gamba PL, Mancia G: Neuroadrenergic and reflex abnormalities in patients with metabolic syndrome. Diabetologia 2005, 48: 1359-1365.

23. Wolk R, Shamsuzzaman AS, Somers VK: Obesity, sleep apnea, and hypertension. Hypertension 2003, 42:1067-1074.

24. Coughlin SR, Mawdsley L, Mugarza JA, Calverley PM, Wilding JP. Obstructive sleep apnoea is independently associated with an increased prevalence of metabolic syndrome. Eur Heart J 2004, 25:735-74I.

25. Grassi G, Seravalle G, Cattaneo BM, Bolla GB, Lanfranchi A, Colombo M, Giannattasio C, Brunani A, Cavagnini F, Mancia G: Sympathetic activation in obese normotensive subjects. Hypertension 1995 25:560-563.

26. Grassi G: Renin-angiotensin-sympathetic crosstalks in hypertension: reappraising the relevance of peripheral interactions. J Hypertens 2001, 19:1713-1716.

27. Egan BM: Insulin resistance and the sympathetic nervous system. Curr Hypertens Rep 2003, 5:247-254.

28. Sarafidis PA, Bakris GL: Non-esterified fatty acids and blood pressure elevation: a mechanism for hypertension in subjects with obesity/insulin resistance? J Hum Hypertens 2007, 2I:12-9.

29. Correia ML, Haynes WG: Obesity-related hypertension: is there a role for selective leptin resistance? Curr Hypertens Rep 2004, 6(3):230-235.

30. Mancia G, Bousquet P, Elghozi JL, Esler M, Grassi G, Julius S, Reid J, Van Zwieten PA: The sympathetic nervous system and the metabolic syndrome. J Hypertens 2007, 25:909-920.
3I. Barnard RJ, Roberts CK, Varon SM, Berger J]: Diet-induced insulin resistance precedes other aspects of the metabolic syndrome. J Appl Physiol 1998, 84:131I-I315.

32. Roberts CK, Barnard RJ, Sindhu RK, Jurczak M, Ehdaie A, Vaziri ND A high-fat, refined-carbohydrate diet induces endothelial dysfunction and oxidant/antioxidant imbalance and depresses NOS protein expression. I Appl Physiol 2005, 98:203-2।

33. Furukawa $S$, Fujita $T$, Shimabukuro $M$, Iwaki $M$, Yamada $Y$, Nakajima Y, Nakayama O, Makishima M, Matsuda M, Shimomura I: Increased oxidative stress in obesity and its impact on metabolic syndrome. I Clin Invest 2004, I 1 4: 1752-I76I.

34. Sarafidis PA, Bakris GL: The antinatriuretic effect of insulin: an unappreciated mechanism for hypertension associated with insulin resistance? Am J Nephrol 2007, 27:44-54.

35. Meigs JB, Larson MG, Fox CS, Keaney JF Jr, Vasan RS, Benjamin EJ: Association of oxidative stress, insulin resistance, and diabetes risk phenotypes: the Framingham Offspring Study. Diabetes Care 2007, 30:2529-2535.

36. Kim JA, Montagnani M, Koh KK, Quon MJ: Reciprocal relationships between insulin resistance and endothelial dysfunction: molecular and pathophysiological mechanisms. Circulation 2006, II 3:1888-1904.

37. Rossi R, Chiurlia E, Nuzzo A, Cioni E, Origliani G, Modena MG: Flowmediated vasodilation and the risk of developing hypertension in healthy postmenopausal women. J Am Coll Cardiol 2004, 44: 1636-1640.

38. Engeli S, Schling P, Gorzelniak K, Boschmann M, Janke J, Ailhaud G: The adipose-tissue renin-angiotensin-aldosterone system: role in the metabolic syndrome? Int J Biochem Cell Biol 2003, 35:807-825.

39. Engeli S, Gorzelniak K, Kreutz R, Runkel N, Distler A, Sharma AM: Co-expression of renin-angiotensin system genes in human adipose tissue. J Hypertens 1999, 17:555-560.

40. Goodfriend TL, Egan BM, Kelley DE: Aldosterone in obesity. Endocr Res 1998, 24:789-796.

4I. Egan BM, Stepniakowski K, Goodfriend TL: Renin and aldosterone are higher and the hyperinsulinemic effect of salt restriction greater in subjects with risk factors clustering. Am J Hypertens 1994, 7:886-893.

42. Bochud M, Nussberger J, Bovet P, Maillard MR, Elston RC, Paccaud F, Shamlaye C, Burnier M: Plasma aldosterone is independently associated with the metabolic syndrome. Hypertension 2006, 48:239-245

43. Kidambi S, Kotchen JM, Grim CE, Raff H, Mao J, Singh RJ, Kotchen TA Association of adrenal steroids with hypertension and the metabolic syndrome in blacks. Hypertension 2007, 49:704-71I.

44. Sowers JR: Insulin resistance and hypertension. Am J Physiol Heart Circ Physiol 2004, 286:HI597-1602.

45. Ridker PM, Wilson PW, Grundy SM: Should C-reactive protein be added to metabolic syndrome and to assessment of global cardiovascular risk? Circulation 2004, 109:28।8-2825.

46. Sesso HD, Buring JE, Rifai N, Blake G], Gaziano JM, Ridker PM: Creactive protein and the risk of developing hypertension. JAMA 2003, 290:2945-295I.

47. Grundy SM: Inflammation, hypertension, and the metabolic syndrome. JAMA 2003, 290(22):3000-3002.

48. Kahaleh MB, Fan PS: Effect of cytokines on the production of endothelin by endothelial cells. Clin Exp Rheumatol 1997. 15:163-167.

49. Brasier AR, Li J, Wimbish KA: Tumor necrosis factor activates angiotensinogen gene expression by the Rel $A$ transactivator. Hypertension 1996, 27: 1009-1017.

50. Pausova Z, Deslauriers B, Gaudet D, Tremblay J, Kotchen TA, Larochelle P: Role of tumor necrosis factor-alpha gene locus in obesity and obesity-associated hypertension in French Canadians. Hypertension 2000, 36:14-19.

5I. Zinman B, Hanley AJ, Harris SB, Kwan J, Fantus IG: Circulating tumor necrosis factor-alpha concentrations in a native Canadian population with high rates of type 2 diabetes mellitus. Clin Endocrinol Metab 1999, 84:272-278.

52. Dorffel Y, Latsch C, Stuhlmuller B, Schreiber S, Scholze S, Burmester GR: Preactivated peripheral blood monocytes in patients with essential hypertension. Hypertension 1999, 34: II3-II7.

53. Fernandez-Real JM, Vayreda M, Richart C, Gutierrez C, Broch M, Vendrell J, Ricart W: Circulating interleukin 6 levels, blood 
pressure, and insulin sensitivity in apparently healthy men and women. J Clin Endocrinol Metab 200I, 86: I I54-II 59.

54. Papanicolaou DA, Petrides JS, Tsigos C, Bina S, Kalogeras KT, Wilder R, Gold PW, Deuster PA, Chrousos GP: Exercise stimulates interleukin-6 secretion: inhibition by glucocorticoids and correlation with catecholamines. Am J Physiol 1996, 27I:E60I-605.

55. Besedovsky HO, del Rey A: Immune-neuro-endocrine interactions: facts and hypotheses. Endocr Rev 1996, 17:64-102.

56. Torpy DJ, Papanicolaou DA, Lotsikas AJ, Wilder RL, Chrousos GP, Pillemer SR: Responses of the sympathetic nervous system and the hypothalamic-pituitary-adrenal axis to interleukin-6: a pilot study in fibromyalgia. Arthritis Rheum 2000, 43:872-880.

57. Takano M, Itoh N, Yayama K, Yamano M, Ohtani R, Okamoto H: Interleukin-6 as a mediator responsible for inflammationinduced increase in plasma angiotensinogen. Biochem Pharmacol 1993, 45:201-206.

58. Parish JM, Adam T, Facchiano L: Relationship of metabolic syndrome and obstructive sleep apnea. J Clin Sleep Med 2007, 3:467-472.

59. Kono M, Tatsumi K, Saibara T, Nakamura A, Tanabe N, Takiguchi $Y$, Kuriyama $T$ : Obstructive sleep apnea syndrome is associated with some components of metabolic syndrome. Chest 2007, I3 I:1387-1392.

60. Lam JC, Ip MS: An update on obstructive sleep apnea and the metabolic syndrome. Curr Opin Pulm Med 2007, 13:484-489.

61. Narkiewicz K, van de Borne PJ, Cooley RL, Dyken ME, Somers VK: Sympathetic activity in obese subjects with and without obstructive sleep apnea. Circulation 1998, 98:772-776.

62. Wolk R, Shamsuzzaman AS, Somers VK: Obesity, sleep apnea, and hypertension. Hypertension 2003, 42:1067-1074.

Publish with Biomed Central and every scientist can read your work free of charge

"BioMed Central will be the most significant development for disseminating the results of biomedical research in our lifetime. "

Sir Paul Nurse, Cancer Research UK

Your research papers will be:

- available free of charge to the entire biomedical community

- peer reviewed and published immediately upon acceptance

- cited in PubMed and archived on PubMed Central

- yours - you keep the copyright

Submit your manuscript here:

http://www.biomedcentral.com/info/publishing_adv.asp
BiolMedcentral 